Article

\title{
Dimensional Analysis under Pythagorean Fuzzy Approach for Supplier Selection
}

\author{
Aldo Joel Villa Silva *®e Luis Asunción Pérez Dominguez@ Erwin Martínez Gómez, \\ Alejandro Alvarado-Iniesta and Iván Juan Carlos Pérez Olguín $\mathbb{D}$ \\ Departamento de Doctorado en Tecnología Ciudad Juárez, Instituto de Ingeniería y Tecnología, Universidad \\ Autónoma de Ciudad Juárez, 32310 Mexico, Mexico; luis.dominguez@uacj.mx (L.A.P.D.); \\ emartine@uacj.mx (E.M.G.); alejandro.alvarado@uacj.mx (A.A.-I.); ivan.perez@uacj.mx (I.J.C.P.O.) \\ * Correspondence: ing.aldojvillasilva@gmail.com; Tel.: +52-656-6882100
}

Received: 24 January 2019; Accepted: 26 February 2019; Published: 6 March 2019

check for updates

\begin{abstract}
The supplier appraisal process is one of the most important decision problems for companies focused on improving supply chain costs. Supplier selection is typically a multi-criteria decision making (MCDM) issue, as there is a lot of uncertain information. In order to overcome this issue, The Pythagorean Fuzzy Set is applied to handle the uncertainties involved in comparing the alternatives, criteria and opinions of decision makers. At the same time, a potential of Dimensional Analysis is a technique which deploys an association of the criteria capturing the interrelationship normally present in MCDM. In this sense, the purpose of this paper is to evaluate the suppliers in a supply chain cycle using Pythagorean Fuzzy Set and Dimensional Analysis. Finally, the applicability of the proposed method is illustrated through numerical examples, and a validation via Spearman correlation and Cronbach's alpha.
\end{abstract}

Keywords: multi-criteria decision making; supplier selection; Pythagorean Fuzzy Set; Dimensional Analysis

\section{Introduction}

In today's competitive world, the selection of suppliers has become a complicated problem that involves a large number of academics and professionals [1]. The selection of the provider depends on a variety of criteria such as characteristics of markets, demands from customers, delivery times, quality, price and service excellence [2,3]. Therefore, choosing the best suppliers can be conflicting in nature. According to Kang et al. [4], a supplier's selection can be modeled as a typical multi-criteria decision making problem.

Moreover, various supplier selection methods such as Analytical Hierarchy Process (AHP), Analytic Network Process (ANP), Artificial Neural Network (ANN), Technique for Order Preference by Similarity to Idal Solution (TOPSIS), Data Envelopment Analysis (DEA), Integer programming, Genetic Algorithms and combinations of any of these tools are observed in the literature [1]. However, in decision making, most of these methods only consider quantitative criteria, and other type of factors-such as incomplete information, qualitative criteria and imprecision preferences-are not included [5].

In this context, the Fuzzy Set method has recently been applied for supplier selection [5]. As per a proposal from Jafarnejad and Aghasi [6], the integration of fuzzy Preference Ranking Organization Methods for Enrichment Evaluations (PROMETHEE) and linear programs for supplier selection under uncertainty. This is applicable in business to allow for the building of road maps for profit maximization. Mavi, Goh and Mavi [7] proposed a Shannon entropy and fuzzy TOPSIS, the first for weighing criteria and the second for ranking suppliers. Their findings show that demand risk is the 
most important factor. On other hand, Bolturk [8] developed the Pythagorean fuzzy extension of the COmbinative Distance-based Assessment (CODAS) method, which is applicable in supplier selection problems that are vague and imprecise. Additionally, the literature shows $[5,6,9,10]$ that most of these methods such as AHP, TOPSIS—including fuzzy versions—and others have the following limitations:

Do not take into account the interrelationship among three or more arguments.

Limited qualitative criteria.

Imprecise preferences of decision makers.

Dimensional Analysis (DA) is able to capture the interrelationship between multiple arguments (or criteria) into single dimensionless indexes [11], making it convenient in multi-criteria decision making (MCDM) problems with different measurement scales [11-13]. The main advantage of DA is that is can integrate the opinions of a group of decision makers (DM) on diverse information, such as alternatives, criteria and the importance of each criteria [11]. Nevertheless, DA is weak using quantitative (crisp) and qualitative (fuzzy) information, which is commonly present in MCDM problems.

On the other hand, Pythagorean Fuzzy Sets (PFS) have become a new generalization of fuzzy sets (FS) and can handle and model uncertain information in a more "flexible" way in the DM process than can Intuitionistic Fuzzy Sets (IFS). The main advantage of PFS is the condition that the square sum of their degree of membership and the degree of non-membership is equal to or less than 1 [14-21]. For example, when a decision maker provides the evaluation information whose membership grade is 0.4 and the degree of non-membership is 0.9 , an IFS cannot address this problem because $0.4+0.9>1$. However, $0.4^{2}+0.9^{2}<1$. That is, a PFS is able to represent this evaluation information [15].

Based on the aforementioned considerations, this research could have industrial application in medium and small enterprises, and may be directed to management, engineers and buyers that tackle the issue of supplier appraisal. Using an integrated tool: an extension of DA with PFS: the qualitative criteria, imprecision preferences of the DMs and interrelationship among the multi-input arguments can be overcame for multi-input arguments. The rest of the paper is organized as follows: In Section 2, the preliminaries of Pythagorean Fuzzy Sets (PFS) and Dimensional Analysis (DA) are given. In Section 3, the methodology of the integration of PFS and DA is given, and an algorithm is proposed in eight steps. In Section 4, two illustrated examples for supplier selection problems are presented, applying the proposed method. This approach is as follows: (1) A sensitivity analysis, (2) a comparative analysis with other fuzzy methods; in addition a Spearman correlation and Cronbach's alpha in order to validate our method; (3) results. Finally, in Section 5, the conclusion is given and suggestions for further research are presented.

\section{Preliminaries}

\subsection{Pythagorean Fuzzy Set (PFS)}

Basic concepts of PFS are the following:

Definition 1. [14,16,20], let X be a universe of discourse. Then IFS I in X is given by:

$$
I=\left\{\left\langle x, \mu_{I}(x), v_{I}(x)\right\rangle \mid x \in X\right\}
$$

Definition 2. [17,20-24], let X be a universe of discourse. A PFS P in X is given by:

$$
P=\left\{\left\langle x, \mu_{P}(x), v_{P}(x)\right\rangle \mid x \in X\right\} .
$$


The degree of indeterminacy $[14,16,23-25]$ is expressed, where $\mu_{P}: X \rightarrow[0,1]$ denotes the degree of membership and $v_{P}: X \rightarrow[0,1]$ denotes the degree of non-membership of the element $x \in X$ to the set $P$. Therefore, the degree of indeterminacy is given by:

$$
\pi_{P}(x)=\sqrt{1-\left(\mu_{P}(x)\right)^{2}-\left(v_{P}(x)\right)^{2}} .
$$

According to Zhang and $\mathrm{Xu}$ [14], for convenience called $\left(\mu_{P}(x), v_{P}(x)\right)$ a PFS denoted by $p=\left(\mu_{P}, v_{P}\right)$.

Definition 3. $[15,16,18]$; for any PFS, $p=(\mu, v), p$ is defined as follows:

$$
s(p)=(\mu)^{2}-(v)^{2}
$$

where $s(p) \epsilon[-1,1]$.

Definition 4. [14,16,18]; for any PFS, $p=(\mu, v)$, the accuracy is defined as follows:

$$
a(p)=(\mu)^{2}+(v)^{2}
$$

where $a(p) \in[0,1]$.

Definition 5. [16,26], if $M, N \in P F S$, and then the operations are defined as follows:

$$
\begin{aligned}
& M^{C}=\left\{\left\langle x, v_{M}(x), \mu_{M}(x)\right\rangle \mid x \in X\right\} \\
& M \subseteq N \text { iff } \forall x \in X, \mu_{M}(x) \leq \mu_{N}(x) \text { and } v_{M}(x) \geq v_{N}(x) \\
& M=N \text { iff } \forall x \in X, \mu_{M}(x)=\mu_{N}(x) \text { and } v_{M}(x)=v_{N}(x) \\
& \Phi_{M}=\{\langle x, 1,0\rangle \mid x \in X\} \\
& \varnothing_{M}=\{\langle x, 0,1\rangle \mid x \in X\} \\
& M \cap N=\left\{\left\langle x, \mu_{M}(x) \wedge \mu_{N}(x), v_{M}(x) \vee v_{N}(x)\right\rangle \mid x \in X\right\} \\
& M \cup N=\left\{\left\langle x, \mu_{M}(x) \vee \mu_{N}(x), v_{M}(x) \wedge V_{N}(x)\right\rangle \mid x \in X\right\} \\
& M \oplus N\left\{\left\langle x, \sqrt{\mu_{M}^{2}(x)+\mu_{N}^{2}(x)-\mu_{M}^{2}(x) \mu_{N}^{2}(x)}, v_{M}(x) v_{N}(x)\right\rangle \mid x \in X\right\} ; \\
& M \ominus N=\left\{\left\langle x, \sqrt{\frac{\mu_{M}^{2}(x)-\mu_{N}^{2}(x)}{1-\mu_{N}^{2}(x)}}, \frac{v_{M}(x)}{v_{N}(x)}\right\rangle \mid x \in X\right\} \text {, if } \mu_{M}(x) \geq \mu_{N}(x), \mu_{M}(x) \\
& \leq \min \left\{\mu_{N}(x), \frac{v_{N}(x) \pi_{M}(x)}{\pi_{N}(x)}\right\} \\
& M \oslash N=\left\{\left\langle x, \frac{\mu_{M}(x)}{\mu_{N}(x)}, \sqrt{\frac{v_{M}^{2}(x)-v_{N}^{2}(x)}{1-v_{N}^{2}(x)}}\right\rangle \mid x \in X\right\}, \text { if } v_{M}(x) \geq v_{N}(x), \mu_{M}(x) \\
& \leq \min \left\{\mu_{N}(x), \frac{\mu_{N}(x) \pi_{M}(x)}{\pi_{N}(x)}\right\} \\
& p^{\lambda}=\left(\mu^{\lambda}, \sqrt{\left.1-\left(1-v^{2}\right)^{\lambda}\right)}\right. \\
& M \otimes N=\left\{\left\langle x, \mu_{M}(x) \mu_{N}(x), \sqrt{v_{M}^{2}(x)+v_{N}^{2}-v_{M}^{2}(x) v_{N}^{2}(x)}\right\rangle \mid x \in X\right\} \\
& \lambda p=\left(\sqrt{\left.1-\left(1-\mu^{2}\right)^{\lambda}, v^{\lambda}\right)} .\right.
\end{aligned}
$$




\subsection{Dimensional Analysis (DA)}

DA is a technique that has been used in the decision making process, particularly for the selection of multi-criteria-type alternatives. DA is an MCDM technique that assumes there is an optimal solution better than the rest, $S^{*}$. DA compares each alternative in evaluation with this ideal alternative to generate an index of similarity, therefore the highest index of similarity is chosen as the best alternative to the MCDM problem [11-13].

Definition 6. Let $a_{l}^{k}(k=1, \ldots, n)(l=1, \ldots m)$ and $S_{l}^{*}=a_{j}^{*}(l=1, \ldots, m)$ represent a database of crisp numbers. $D A$ is defined as follows:

$$
I S_{i}\left(a_{1}^{i}, a_{2}^{i}, \ldots, a_{m}^{i}\right)=\prod_{j=1}^{m}\left(\frac{a_{j}^{i}}{S_{l}^{*}}\right)^{w_{j}}
$$

where $I S_{i}$ is called the index of similarity for alternative $i ; a_{l}^{k}$ is the crisp evaluation of criterion l for alternative $i$; $S_{l}^{*}$ is the crisp value of the ideal alternative for criterion $l ; w_{j}(z=1, \ldots, m)$ is the crisp weight for criterion $l$.

\section{Methodology}

In this section, we introduced the Pythagorean Fuzzy Dimensional Analysis (PFDA) approach for MCDM problems.

Based on Equation (18), the definition of PFDA is given as follows.

Definition 7. Pythagorean Fuzzy Set Dimensional Analysis method. Let $\omega_{j}^{i}=\left(\mu_{w_{j}^{i}}, v_{w i_{j}^{i}}\right)(i=1,2, \ldots n)$ $(j=1,2 \ldots m)$ and $S_{j}^{i}=\left(\mu_{w i}, v_{w i}\right)(j=1,2 \ldots m)$ be a collection of $P F_{S}$, if

$$
\operatorname{PFIS}_{i}\left(\omega_{1}^{i}, \omega_{2}^{i}, \ldots, \omega_{m}^{i}\right)=\left(\otimes_{j=1}^{m}\left(\frac{\omega_{j}^{i}}{S_{j}^{*}}\right)^{T_{j}}\right)=\left(\otimes_{j=1}^{m}\left(\xi_{j}^{i}\right)^{T_{j}}\right),
$$

then PFIS $i$ is named "Pythagorean Fuzzy Index of Similarity" for alternative $i$. Here, $\omega_{j}^{i}$ is the Pythagorean fuzzy evaluation of criterion $j$ for alternative $i, S_{j}^{*}$ is the Pythagorean fuzzy value of the "ideal alternative" for criterion $j$, and $T_{j}(j=1,2, \ldots m)$ is the corresponding crisp weight for criterion $j$ satisfying $T_{j}>$ $0(j=1,2, \ldots m)$ and $\sum_{j=1}^{m} T_{j}=1$.

Based on Equations (3)-(7) of the PFS described in Section 2, the next results can be derived.

Theorem 1. Let $\xi_{j}^{i}=\left(\mu_{\xi_{j}}, v_{\xi_{j}}\right)(i=1,2, \ldots, n)(j=1,2, \ldots, m)$ be a collection of PFS. Therefore, the aggregated value, by using PFIS is the following:

$$
\operatorname{PFIS}_{i}\left(\omega_{1}^{i}, \omega_{2}^{i}, \ldots, \omega_{m}^{i}\right)=\left(\begin{array}{l}
m \\
\otimes=1
\end{array}\left(\xi_{j}^{i}\right)^{T_{j}}\right)=\left(\prod_{j=1}^{m}\left(\mu_{\xi_{j}^{i}}\right)^{T_{j}}, \sqrt{1-\prod_{j=1}^{m}\left(1-\left(v_{\xi_{j}}\right)^{2}\right)^{T_{j}}}\right) .
$$

Proof. Based on Equation (15) described in Section 2, we can obtained Equation (23):

$$
\xi_{j}^{i}=\frac{\omega_{j}^{i}}{S_{j}}=\left(\frac{\mu_{\omega_{j}^{i}}}{\mu_{\omega_{j}^{*}}}, \frac{v_{\omega_{j}^{i}}-v_{\omega_{j}^{*}}}{1-v_{\omega_{j}^{*}}}\right)=\left(\mu_{\xi_{j}^{i}}, v_{\xi_{j}^{i}}\right) .
$$


Then, by Equation (16):

$$
\left(\xi_{j}^{i}\right)^{T_{j}}=\left(\mu_{\xi_{j}^{i}} T_{j}, \sqrt{1-\left(1-v_{\xi_{j}^{i}}\right)^{T_{j}}}\right) .
$$

Also, according to Equation (17):

$$
\begin{gathered}
\quad m \quad\left(\xi_{j}^{i}\right)^{T_{j}}= \\
\left.\underset{j=1}{\left(\left(\mu_{\xi_{1}^{i}} T_{1}\right)\left(\mu_{\xi_{2}^{i}} T_{j}\right) \ldots\left(\mu_{\xi_{m}^{i}}^{T_{m}}\right), \sqrt{1-\left(\left(1-v_{\xi_{1}^{i}}{ }^{2}\right)^{T_{1}}\left(1-v_{\xi_{2}^{i}}{ }^{2}\right)^{T_{j}} \ldots\left(1-v_{\xi_{m}}{ }^{2}\right)^{T_{j}}\right.}\right)}\right)= \\
\left(\prod_{j=1}^{m}\left(\mu_{\xi_{j}^{i}}\right)^{T_{j}}, \sqrt{1-\prod_{j=1}^{m}\left(1-\left(v_{\xi_{j}}\right)^{2}\right)^{T_{j}}}\right) .
\end{gathered}
$$

This completes the proof of Theorem 1.

When the MCDM problem contains both types of criteria, benefit criteria $(B N)$ and cost criteria (C), the following has to be considered. If $\alpha_{j} \in B N$; then:

$$
\xi_{j}^{i}=\frac{\alpha_{j}^{i}}{S_{j}}=\left(\frac{\mu_{\omega_{j}^{i}}}{\mu_{\omega_{j}^{*}}}, \sqrt{\frac{v_{\omega_{j}^{i}}-v_{\omega}}{1-v_{\omega_{j}^{*}}}}\right)=\left(\mu_{\xi_{j}^{i},} v_{\xi_{j}^{i}}\right) \quad j \in B N .
$$

Otherwise, if $\alpha_{j} \in C$; then,

$$
\xi_{j}^{\prime i}=\frac{S_{j}}{\alpha_{j}^{i}}=\left(\frac{\mu_{\omega_{j}^{*}}}{\mu_{\omega_{j}^{i}}}, \sqrt{\frac{v_{\omega_{j}^{*}}-v_{\omega_{j}^{i}}}{1-v_{\omega_{j}^{i}}}}\right)=\left(\mu_{\xi_{j}^{\prime i}}, v_{\xi_{j}^{\prime i}}\right) \quad j \in C .
$$

Following the next conditions,

$$
\begin{aligned}
& \mu_{\omega_{j}^{*}}=\left(\left(\max \mu_{\omega_{j}^{i}} \mid j \in B N\right),\left(\min \mu_{\omega_{j}^{i}} \mid j \in C\right)\right) \\
& v_{\omega_{j}^{*}}=\left(\left(\min v_{\omega_{j}^{i}} \mid j \in B N\right),\left(\max v_{\omega_{j}^{i}} \mid j \in C\right)\right),
\end{aligned}
$$

where

$$
S_{j}=\left(\mu_{\omega_{j}^{*}}, v_{\omega_{j}^{*}}\right) .
$$

If $D M_{k}=\left\{\mu_{k}, v_{k}, \pi_{k}\right\}$ is a Pythagorean fuzzy number, the weight of DM [27] is represented by:

$$
\varepsilon_{k}=\frac{\left(\mu_{k}+\pi_{k}\left(\mu_{k} /\left(\mu_{k}+v_{k}\right)\right)\right)}{\sum_{k=1}^{l}\left(\mu_{k}+\pi_{k}\left(\mu_{k} /\left(\mu_{k}+v_{k}\right)\right)\right)}
$$

where $\sum_{k=1}^{l} \varepsilon_{k}=1$.

Preferences of the DM need to be gathered in a Pythagorean fuzzy matrix [27]:

$$
\begin{gathered}
X_{k l}=\operatorname{PFWA}\left(X_{k l}^{(1)}, X_{k l}^{(2)}, \ldots, X_{k l}^{(t)}, \ldots, X_{k l}^{(z)}\right)=\omega_{1} X_{k l}^{(1)} \oplus \omega_{2} X_{k l}^{(2)} \oplus \ldots \oplus \omega_{z} X_{k l}^{(z)} \oplus \ldots \oplus \\
\omega_{j} X_{k l}^{(t)}=\left[\sum_{k=1}^{l}\left(\left(\omega \mu_{k l}^{(z)}\right),\left(\omega v_{k l}^{(z)}\right)\right)\right] .
\end{gathered}
$$

The algorithm for proposed PF-DA below.

In accordance with above analysis, PF-DA is defined in the following steps:

Step 1: Define the Pythagorean decision matrix.

Step 2: Select the ideal solution in accordance with $B N$ or $C$ criteria values. 
Step 3: Establish criteria weights, use Equations (30) and (31).

Step 4: Standardized matrix-use Equation (25) for $B N$ criteria, Equation (26) for $C$ criteria.

Step 5: Standardized matrix elevated in accordance with criteria weights, use Equation (16).

Step 6: Generate PFIS index, use Equation (21).

Step 7: Establish the highest index of the index of similarity (IS), use Equation (4).

Step 8: Establish the ranking, with highest values to lowest values.

\section{Numerical Illustration}

In this section, we consider a decision making problem that a manufacturing company is facing at Ciudad Juárez, Mexico. Mainly the problem is focused on supplier selection to achieve cost reductions at the finished goods manufacturing phase. The company is considering five suppliers for electronics items. Suppliers are defined by $A=\left\{A_{1}, A_{2}, A_{3}, A_{4}, A_{5}\right\}$. Four criteria involved are defined as:

Price $\left(X_{1}\right)$ : the most minimum values are selected.

Facility $\left(X_{2}\right)$ : great assessments are selected.

Lead time $\left(X_{3}\right)$ : high assessments are selected.

Quality $\left(X_{4}\right)$ : great assessments are selected.

Step 1: In accordance with DM evaluations, the Pythagorean fuzzy decision matrix is defined as follows:

$$
\left[\begin{array}{llll}
\{0.10,0.97\} & \{0.25,0.90\} & \{1.00,0.00\} & \{0.80,0.44\} \\
\{0.40,0.87\} & \{0.60,0.71\} & \{0.50,0.80\} & \{0.70,0.60\} \\
\{0.96,0.04\} & \{0.96,0.04\} & \{0.96,0.04\} & \{0.10,0.97\} \\
\{0.71,0.50\} & \{0.10,0.97\} & \{0.10,0.97\} & \{0.25,0.92\} \\
\{0.50,0.80\} & \{0.40,0.87\} & \{0.71,0.50\} & \{0.50,0.80\}
\end{array}\right] .
$$

Step 2: Establish the ideal solution in accordance with criteria values:

$$
S^{+}:\{0.10,0.97\}\{0.96,0.04\}\{1.00,0.00\}\{0.80,0.44\} .
$$

Step 3: Establish the criteria weights, use Equations (30) and (31):

$$
W_{\left\{X_{1}, X_{2}, X_{3}, X_{4}\right\}}=\left[\begin{array}{l}
\{0.24\} \\
\{0.24\} \\
\{0.22\} \\
\{0.31\}
\end{array}\right] .
$$

Step 4: In order to standardize the matrix, use Equations (25) and (26) in accordance with $B N$ or C:

$$
\left[\begin{array}{lllll}
\{1.0000,0.0000\} & \{0.2604,0.8998\} & \{1.0000,0.0000\} & \{1.0000,0.0000\} \\
\{0.2500,0.6564\} & \{0.6250,0.7094\} & \{0.5000,0.8000\} & \{0.8750,0.4543\} \\
\{0.1042,0.9692\} & \{1.0000,0.0000\} & \{0.9600,0.0400\} & \{0.1250,0.9627\} \\
\{0.1408,0.8585\} & \{0.1042,0.9700\} & \{1.0000,0.9700\} & \{0.3125,0.8997\} \\
\{0.2000,0.7139\} & \{0.4167,0.8698\} & \{0.7100,0.5000\} & \{0.6250,0.7440\}
\end{array}\right]
$$

Step 5: Then, each criteria column in the standardized matrix is elevated with criteria weights; use Equation (16):

$$
\left[\begin{array}{lllll}
\{1.0000,0.0000\} & \{0.7240,0.5731\} & \{1.0000,0.0000\} & \{1.0000,0.0000\} \\
\{0.7170,0.3557\} & \{0.8930,0.3932\} & \{0.8590,0.4487\} & \{0.9590,0.2629\} \\
\{0.5811,0.6997\} & \{1.0000,0.0000\} & \{0.9910,0.0188\} & \{0.5250,0.7451\} \\
\{0.6247,0.5237\} & \{0.5810,0.7019\} & \{0.6030,0.6806\} & \{0.6970,0.6340\} \\
\{0.6796,0.3965\} & \{0.8100,0.5362\} & \{0.9270,0.2476\} & \{0.8640,0.4703\}
\end{array}\right]
$$


Step 6: Then, to generate an index of similarity, PFIS $_{i}$, use Equation (21):

$$
\left[\begin{array}{ll}
0.7240 & 0.5730 \\
0.5276 & 0.6720 \\
0.3023 & 0.8790 \\
0.1525 & 0.9390 \\
0.4416 & 0.7490
\end{array}\right]
$$

Step 7: To obtain the highest index of similarity, use Equation (4):

$$
\left[\begin{array}{c}
0.1958 \\
-0.1726 \\
-0.6817 \\
-0.8585 \\
-0.3661
\end{array}\right]
$$

Step 8: Establish the ranking; the results reveal that:

$$
A_{1}>A_{2}>A_{5}>A_{3}>A_{4} .
$$

Therefore $A_{1}$ is selected as the best supplier, and the highest index of similarity is chosen as the best alternative.

Illustration Example 2

In this example taken from the literature [8], an entrepreneur wants to select a supplier. Suppliers are defined by $P=\left\{P_{1}, P_{2}, P_{3}, P_{4}, P_{5}\right\}$, and the evaluation criteria are defined as:

Product Quality $\left(X_{1}\right): B N$ criteria.

Delivery Compliance $\left(X_{2}\right)$ : $B N$ criteria.

Price $\left(X_{3}\right)$ : high assessment $C$ criteria.

Production Capability $\left(X_{4}\right): C$ criteria.

Technological Capability $\left(X_{5}\right): C$ criteria.

Step 1: A linguistic evaluation process is preferred since expert's opinions, and then the Pythagorean fuzzy decision matrix is defined by DMs:

$$
\left[\begin{array}{lllll}
\{0.22,0.65\} & \{0.47,0.56\} & \{0.29,0.51\} & \{0.55,0.76\} & \{0.28,0.69\} \\
\{0.67,0.20\} & \{0.23,0.73\} & \{0.39,0.45\} & \{0.61,0.70\} & \{0.37,0.61\} \\
\{0.41,0.49\} & \{0.42,0.59\} & \{0.34,0.41\} & \{0.65,0.68\} & \{0.48,0.58\} \\
\{0.55,0.48\} & \{0.63,0.55\} & \{0.46,0.40\} & \{0.67,0.67\} & \{0.65,0.57\}
\end{array}\right] .
$$

Step 2: Establish the ideal solution in accordance with criteria values:

$$
S^{+}:\{0.67,0.20\}\{0.63,0.55\}\{0.29,0.51\}\{0.55,0.76\}\{0.28,0.69\} .
$$

Step 3: Weights are assigned to each criterion by the experts:

$$
W_{\left\{X_{1}, X_{2}, X_{3}, X_{4}\right\}}=\left[\begin{array}{l}
\{0.25\} \\
\{0.10\} \\
\{0.50\} \\
\{0.10\} \\
\{0.05\}
\end{array}\right] .
$$


Step 4: In order to standardize the matrix, use Equations (26) and (27) in accordance with $B N$ or $C$ :

$$
\left[\begin{array}{llllll}
\{3.0455,0.6312\} & \{1.3404,0.1262\} & \{1.0000,0.0000\} & \{1.0000,0.0000\} & \{1.0000,0.0000\} \\
\{1.0000,0.2000\} & \{2.7391,0.7300\} & \{1.3448,0.2687\} & \{1.1091,0.4144\} & \{1.3214,0.4070\} \\
\{1.6341,0.4900\} & \{1.5000,0.5900\} & \{1.1724,0.3326\} & \{1.1818,0.4629\} & \{1.7143,0.4588\} \\
\{1.2182,0.4800\} & \{1.0000,0.5500\} & \{1.5862,0.0000\} & \{1.2182,0.4833\} & \{2.3214,0.4733\}
\end{array}\right]
$$

Step 5: Then, each criteria column in the standardized matrix is elevated with criteria weights; use Equation (18):

$$
\left[\begin{array}{lllll}
\{1.3210,0.3454\} & \{1.0297,0.0400\} & \{1.0000,0.0000\} & \{1.0000,0.0000\} & \{1.0000,0.0000\} \\
\{1.0000,0.1008\} & \{1.1060,0.2707\} & \{1.1597,0.1918\} & \{1.0104,0.1366\} & \{1.0140,0.0949\} \\
\{1.1306,0.2576\} & \{1.0414,0.2047\} & \{1.0828,0.2386\} & \{1.0168,0.1544\} & \{1.0273,0.1084\} \\
\{1.0506,0.2517\} & \{1.0000,0.1881\} & \{1.1294,0.0000\} & \{1.0199,0.1620\} & \{1.0430,0.1122\}
\end{array}\right]
$$

Step 6: Then, to generate an index of similarity, PFIS $_{i}$, use Equation (22):

$$
\left[\begin{array}{ll}
1.3603 & 0.3475 \\
1.3141 & 0.3752 \\
1.3318 & 0.4314 \\
1.4076 & 0.3624
\end{array}\right]
$$

Step 7: To obtain the highest index of similarity, use Equation (4):

$$
\left[\begin{array}{l}
1.7297 \\
1.5862 \\
1.5875 \\
1.8499
\end{array}\right]
$$

Step 8: Establish the ranking; the results reveal that:

$$
P_{4}>P_{1}>P_{3}>P_{2} .
$$

Therefore $P_{4}$ is selected as the best supplier; the highest index of similarity is chosen as the best alternative.

\subsection{Sensitivity Analysis}

Different weights are assigned by changing the criteria weights to those obtained by PF-DA in order to observe how much it would influence the final rankings of alternatives. In the first example, we changed the weights of criteria as is shown in Table 1.

Table 1. Example 1 sensitivity analysis.

\begin{tabular}{ccccc}
\hline C1 & C2 & C3 & C4 & Rankings \\
\hline 0.24 & 0.24 & 0.22 & 0.31 & $A 1>A 2>A 5>A 3>A 4$ \\
0.25 & 0.25 & 0.25 & 0.25 & $A 1>A 2>A 5>A 3>A 4$ \\
0.2 & 0.2 & 0.3 & 0.3 & $A 1>A 2>A 5>A 3>A 4$ \\
0.3 & 0.3 & 0.2 & 0.2 & $A 1>A 2>A 5>A 3>A 4$ \\
0.1 & 0.3 & 0.2 & 0.4 & $A 1>A 2>A 5>A 3>A 4$ \\
0.5 & 0.2 & 0.15 & 0.15 & $A 1>A 2>A 5>A 3>A 4$ \\
\hline
\end{tabular}

In the second example, we changed the weights of criteria as is shown in Table 2. 
Table 2. Example 2 sensitivity analysis.

\begin{tabular}{cccccc}
\hline $\boldsymbol{C 1}$ & $\boldsymbol{C 2}$ & C3 & C4 & C5 & Rankings \\
\hline 0.25 & 0.1 & 0.5 & 0.1 & 0.05 & $P 4>P 1>P 3>P 2$ \\
0.1 & 0.1 & 0.3 & 0.4 & 0.1 & $P 4>P 2>P 3>P 1$ \\
0.15 & 0.15 & 0.3 & 0.2 & 0.2 & $P 4>P 3>P 2>P 1$ \\
0.1 & 0.1 & 0.4 & 0.2 & 0.2 & $P 4>P 2>P 3>P 1$ \\
0.3 & 0.1 & 0.15 & 0.15 & 0.3 & $P 4>P 3>P 1>P 2$ \\
0.2 & 0.2 & 0.2 & 0.2 & 0.2 & $P 3>P 4>P 2>P 1$ \\
\hline
\end{tabular}

\subsection{Comparative Analysis}

In accordance with example 1, using the PF-Multi-O bjective Optimization based on Ratio Analysis (MOORA) method, the results were the following:

$$
A_{1}>A_{2}>A_{3}>A_{5}>A_{4} .
$$

Furthermore, applying the PF-Technique for Order Preference by Similarity to Ideal Solution (TOPSIS) method [15], we obtained the following results in Table 3.

Table 3. PF-TOPSIS closeness and rank.

\begin{tabular}{rccc}
\hline $\boldsymbol{D}\left(\boldsymbol{X}_{\boldsymbol{i}}, \boldsymbol{X}^{-}\right)$ & $\boldsymbol{D}\left(\boldsymbol{X}_{\boldsymbol{i}}, \boldsymbol{X}^{+}\right)$ & Closeness $\left(\boldsymbol{X}_{\boldsymbol{i}}\right)$ & Rank \\
\hline 0.7063 & 0.2062 & 0.43059021 & 1 \\
\hline 0.3355 & 0.3955 & -1.23888967 & 2 \\
\hline 0.4937 & 0.4743 & -1.30058103 & 3 \\
\hline 0.2427 & 0.8114 & -3.4439003 & 5 \\
\hline 0.3559 & 0.4981 & -1.69490467 & 4 \\
\hline & Then we have: $A_{1}>A_{2}>A_{3}>A_{5}>A_{4}$.
\end{tabular}

The Spearman correlation coefficient is based on the ranked values for each variable rather than the raw data. Spearman correlation is often used to evaluate relationships involving ordinal variables [28]. Table 4 shows the rankings to calculate the Spearman correlation coefficient $[28,29]$ is given by:

$$
r_{s}=1-\frac{6 * \sum_{i=1}^{n} d_{i}^{2}}{n^{3}-n}
$$

Table 4. Spearman correlation calculation for PF-DA, PF-MOORA and PF-TOPSIS.

\begin{tabular}{cccccc}
\hline Alternative & PF-DA Ranking & PF-MOORA Ranking & PF-TOPSIS Ranking & $\boldsymbol{d}$ & $\boldsymbol{d}^{2}$ \\
\hline$A 1$ & 1 & 1 & 1 & 0 & 0 \\
$A 2$ & 2 & 2 & 2 & 0 & 0 \\
$A 3$ & 4 & 3 & 3 & 1 & 1 \\
$A 4$ & 5 & 5 & 5 & 0 & 0 \\
$A 5$ & 3 & 4 & 4 & 1 & 1 \\
\hline
\end{tabular}

When $n=5$, and $\sum_{i=1}^{n} d_{i}^{2}=2$, then we have the following:

$$
\mathrm{r}_{\mathrm{s}}=1-\frac{6 * 2}{5^{3}-5}=0.9 .
$$

On other hand, Cronbach's alpha [30-32] is calculated using SPSS as is shown in Table 5. 
Table 5. Reliability statistics for PF-DA, PF-MOORA and PF-TOPSIS.

\begin{tabular}{ccc}
\hline Cronbach's Alpha & Cronbach's Alpha Based on the Typified Elements & $N$ of Elements \\
\hline 0.977 & 0.977 & 3 \\
\hline
\end{tabular}

The Figure 1 is a graphic with the ranking comparison for PF-DA, PF MOORA and PF-TOPSIS.

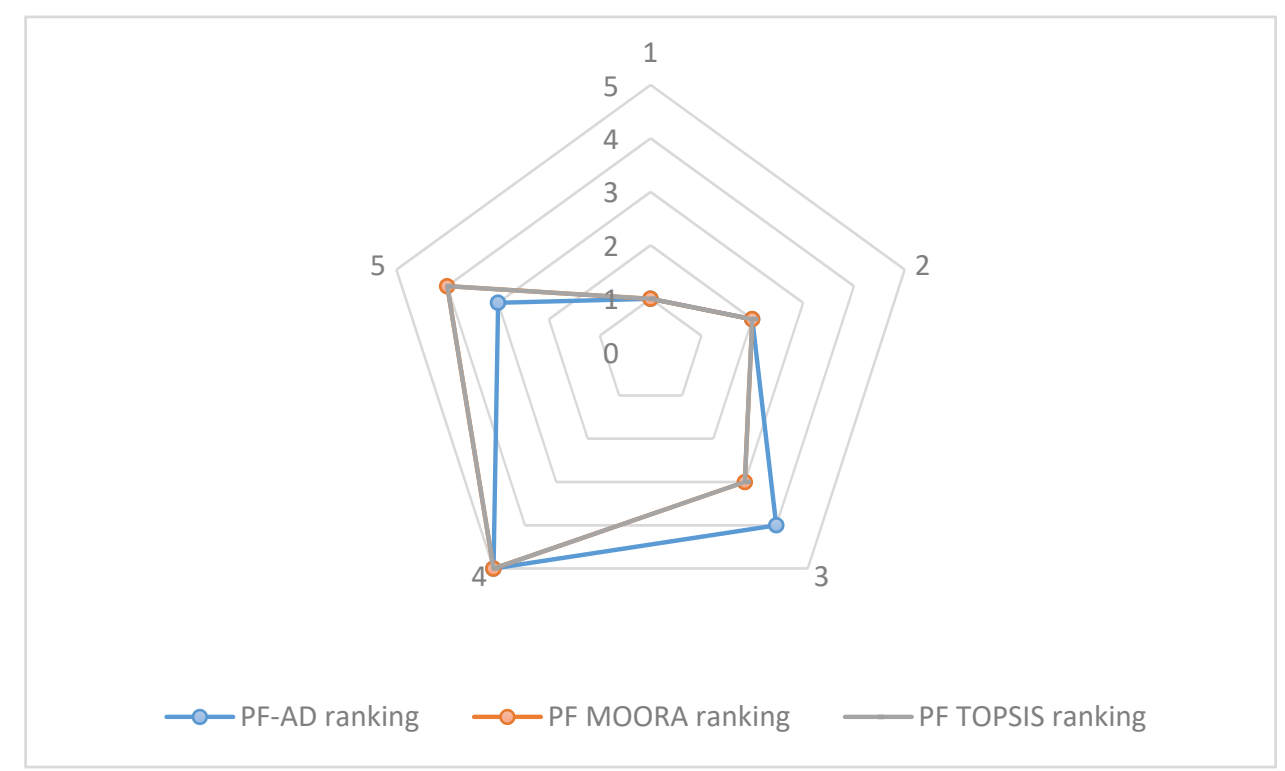

Figure 1. PF-DA vs. PF-MOORA vs. PF-TOPSIS rankings.

In accordance with example 2, using the PF-CODAS method, the results show the following:

$$
P_{4}>P_{1}>P_{2}>P_{3}
$$

Table 6 shows the rankings to calculate the Spearman correlation coefficient [28,29], for illustration example 2:

Table 6. Spearman correlation calculation for PF-DA and PF-CODAS

\begin{tabular}{ccccc}
\hline Alternative & PF-DA Ranking & PF CODAS Ranking & $d$ & $d^{2}$ \\
\hline P1 & 4 & 4 & 0 & 0 \\
P2 & 1 & 1 & 0 & 0 \\
P3 & 3 & 2 & 1 & 1 \\
P4 & 2 & 3 & 1 & 1 \\
\hline
\end{tabular}

When $n=4$, and $\sum_{i=1}^{n} d_{i}^{2}=2$, then we have the following:

$$
r_{S}=1-\frac{6 * 2}{4^{3}-4}=0.8
$$

The Figure 2 is a graphic with the ranking comparison for PF-DA and PF-CODAS. 


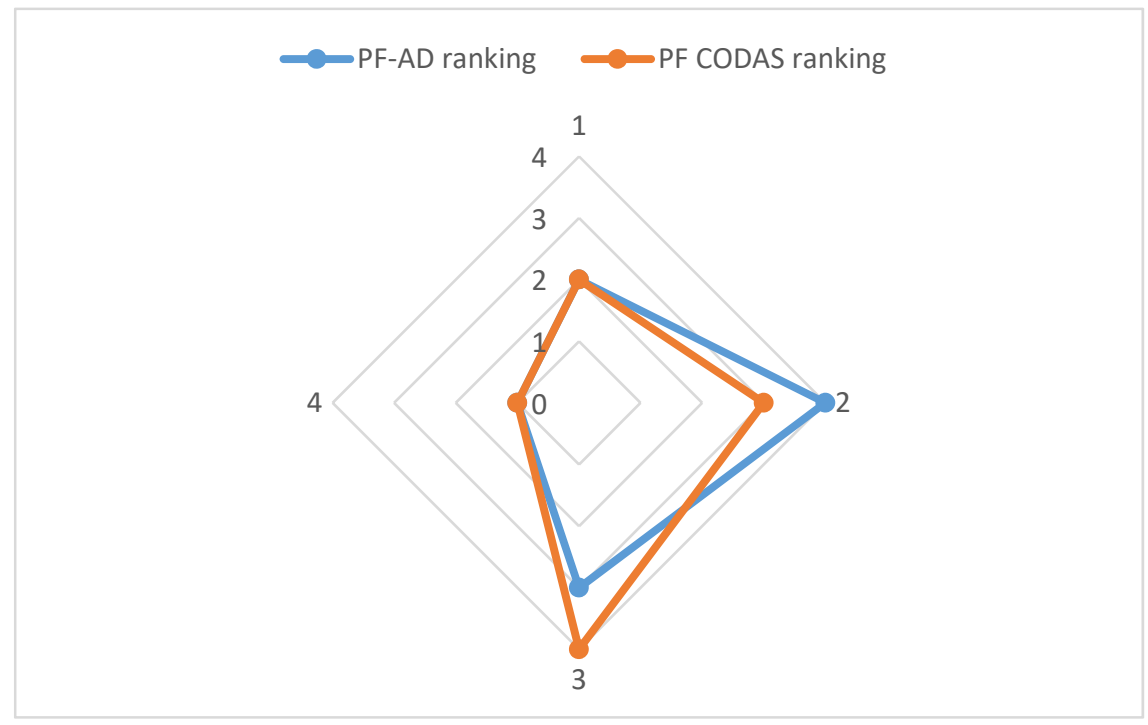

Figure 2. PF-DA vs. PF-CODAS rankings.

On other hand, Cronbach's alpha [30-32] is calculated using SPSS as is shown in Table 7.

Table 7. Reliability statistics for PF-DA and PF-CODAS.

\begin{tabular}{cc}
\hline Cronbach's Alpha & $N$ of Elements \\
\hline 0.889 & 2 \\
\hline
\end{tabular}

\subsection{Results}

Due the PFS satisfies the condition that the square sum of their degree of membership and the degree of non-membership was equal to or less than 1 [14,16-21], the PFS is able to represent the evaluation information [15]; then we presented two illustrated examples using PFS.

In illustration example 1, for PF-DA, PF-MOORA and PF-TOPSIS, where $A_{1}$ was selected as the best supplier, the highest index of similarity was chosen as the optimal alternative. The result shows that the Spearman correlation was 0.9 , which proved that there is a substantial correspondence between our approach, PF-DA, and the two MCDM approaches stated in the literature, namely PF-MOORA and PF-TOPSIS. On other hand, the Cronbach's alpha was 0.977, which is a high value and indicates strong consistency [33]. This means that PF-DA is suitable for dealing with MCDM problems. Moreover, the integration of PF-DA provides advantages over PF-MOORA and PF-TOPSIS as DA attempts to integrate the opinions of a group of decision makers (DM) on diverse information, including alternatives, criteria and the importance of such criteria [11], whereas MOORA and TOPSIS do not.

On other hand, in illustration example 2, for PF-DA and PF-CODAS, $P_{4}$ was selected as the best supplier as it presented the highest index of similarity, indicating the optimal alternative. However, in CODAS the negative ideal solution is considered [8], while in DA the positive ideal solution is considered [11,12]. The Spearman correlation was 0.8 , which means that there is substantial similarity between the PF-DA and PF-CODAS approaches. The Cronbach's alpha was 0.889, which is a high value and indicates strong consistency [33].

\section{Conclusions}

In this paper we introduced a method of the Pythagorean Fuzzy Dimensional Analysis (PF-DA) in fuzzy forecasting decision problems. Forecasts are interesting because they can counteract adverse actions and simulate decisions. Therefore, it is necessary to use aggregation operators and methods that cope well with uncertainty and inaccuracy in forecasts [33]. In this sense, the DA method is 
extended with PFS in order to deal with commonly involved problems in MCDM such as the imprecise preferences of DMs and their interrelationships. Thus, the PF-DA method is developed in eight steps. Furthermore, the application of the proposed method is illustrated by numerical examples that demonstrate that the method is suitable for supplier selection. The Spearman correlation and Cronbach's alpha values show that PF-DA is suitable to deal with MCDM problems. In future, works concerning PF-DA could focus on dealing with other kinds of MCDM problems such as: project selection, investment selection, machine selection, manufacturing systems, staff selection, etc.

Author Contributions: Conceptualization, A.J.V.S. and L.A.P.D.; methodology, A.J.V.S. and L.A.P.D.; validation, A.J.V.S. and I.J.C.P.O.; formal analysis, A.J.V.S.; investigation, A.J.V.S.; resources, E.M.G.; writing-original draft preparation, E.M.G. and A.A.-I.; writing—review and editing, A.J.V.S. and L.A.P.D.; supervision, L.A.P.D.; Authors read and approved the final manuscript.

Funding: CONACYT (Consejo Nacional de Ciencia y Tecnología), and UACJ (Universidad Autónoma de Cd. Juarez).

Conflicts of Interest: The authors declare no conflict of interest.

\section{References}

1. Sultana, M.N.; Habibur, R.; Mamun, A.A. Multi Criteria Decision Making Tools for Supplier Evaluation and Selection: A Review. Eur. J. Adv. Eng. Technol. 2016, 3, 56-65.

2. Gurung, S.; Phipon, R. Multi-criteria decision making for supplier selection using AHP and TOPSIS method. Int. J. Eng. Invent. 2016, 6, 2278-7461. [CrossRef]

3. Shahryari, N.A.; Olfat, L.; Esmaeili, A.; Rostamzadeh, R.; Antuchevičienè, J. Using fuzzy Choquet Integral operator for supplier selection with environmental considerations. J. Bus. Econ. Manag. 2016, 17, 503-526. [CrossRef]

4. Kang, B.; Hu, Y.; Deng, Y.; Zhou, D. A New Methodology of Multicriteria Decision-Making in Supplier Selection Based on Z Numbers. Math. Probl. Eng. 2016, 2016, 8475987. [CrossRef]

5. Makui, A.; Gholamian, M.R. A Hybrid Intuitionistic Fuzzy Multi-criteria Group Decision Making Approach for Supplier Selection. J. Optim. Ind. Eng. 2016, 20, 61-73.

6. Jafarnejad, A.; Aghasi, E. An Integration between Fuzzy PROMETHEE and Fuzzy Linear Program for Supplier Selection Problem: Case Study. J. Appl. Math. Model. Comput. 2015, 4, 79-88. [CrossRef]

7. Mavi, R.K.; Goh, M.; Mavi, N.K. Supplier Selection with Shannon Entropy and Fuzzy TOPSIS in the Context of Supply Chain Risk Management. In Proceedings of the 12th International Strategic Management Conference ISMC 2016, Antalya, Turkey, 28-30 October 2016. Also published in Procedia Soc. Behav. Sci. 2016, 235, 216-225. [CrossRef]

8. Bolturk, E. Pythagorean fuzzy CODAS and its application to supplier selection in a manufacturing firm. J. Enterp. Inf. Manag. 2018, 31, 550-564. [CrossRef]

9. Zhu, B.; Xu, Z. Extended hesitant fuzzy sets. Technol. Econ. Dev. Econ. 2016, 22, 100-121. [CrossRef]

10. Liu, P.; Qin, X. Maclaurin symmetric mean operators of linguistic intuitionistic fuzzy numbers and their application to multiple-attribute decision-making. J. Exp. Theor. Artif. Intell. 2017, 29, 1173-1202. [CrossRef]

11. Perez-Domnguez, L.; Alvarado-Iniesta, A.; Garca-Alcaraz, J.L.; Valles-Rosales, D.J. Intuitionistic fuzzy dimensional analysis for multi-criteria decision making. Iran. J. Fuzzy Syst. 2018, 15, 17-40.

12. García, J.L.; Ju, C. Evaluación y Selección de Tractores Agrícolas con Análisis Dimensional. Acad. J. Rev. Ing. Ind. 2010, 4, 1-8.

13. Perez-Domnguez, L.; Alvarado-Iniesta, A.; Garca-Alcaraz, J.L.; Valles-Rosales, D.J. Análisis dimensional difuso Intuicionista para la selección de personal. In Proceedings of the Congreso Internacional de Investigación Academia Journals 2015, Ciudad Juárez, Chihuahua, Mexico, 20-24 April 2015; Volume 2.

14. Zhang, X.; Xu, Z. Extension of TOPSIS to Multiple Criteria Decision Making with Pythagorean Fuzzy Sets Extension of TOPSIS to Multiple Criteria Decision Making with Pythagorean Fuzzy Sets. J. Int. Syst. Intell. 2014, 29, 1061-1078. [CrossRef]

15. Naz, S.; Ashraf, S.; Akram, M. A Novel Approach to Decision-Making with Pythagorean Fuzzy Information. Mathematics 2018, 6, 95. [CrossRef] 
16. Peng, X.; Yuan, H.; Yang, Y. Pythagorean Fuzzy Information Measures and Their Applications. Int. J. Intell. Syst. 2017, 32, 991-1029. [CrossRef]

17. Liang, W.; Zhang, X.; Liu, M. The maximizing deviation method based on interval-valued pythagorean fuzzy weighted aggregating operator for multiple criteria group decision analysis. Discret. Dyn. Nat. Soc. 2015, 2015, 746572. [CrossRef]

18. Sajjad, M.; Khan, A. Pythagorean fuzzy prioritized aggregation operators and their application to multi-attribute group decision making. Granul. Comput. 2018. [CrossRef]

19. Mardani, A.; Nilashi, M.; Zavadskas, E.K.; Awang, S.R.; Zare, H.; Jamal, N.M. Decision Making Methods Based on Fuzzy Aggregation Operators: Three Decades Review from 1986 to 2017. Int. J. Inf. Technol. Decis. Mak. 2018, 17, 391-466. [CrossRef]

20. Wei, G.; Lu, M.A.O. Dual hesitant pythagorean fuzzy Hamacher aggregation operators in multiple attribute decision making. Arch. Control Sci. 2017, 27, 365-395. [CrossRef]

21. Wei, G. Models for Green Supplier Selection in Green Supply Chain Management with Pythagorean 2-Tuple Linguistic Information. IEEE Access 2018, 6, 18042-18060. [CrossRef]

22. Yager, R.R. Pythagorean fuzzy subsets. In Proceedings of the Joint IFSA world congress and NAFIPS annual Meeting, Edmonton, AB, Canada, 24-28 June 2013; pp. 57-61.

23. Xu, Q.; Yu, K.; Zeng, S.; Liu, J. Pythagorean fuzzy induced generalized owa operator and its application to multi-attribute group decision making. Int. J. Innov. Comput. Inf. Control 2017, 13, 1527-1536.

24. Rahman, K.; Ali, A. Some Interval-Valued Pythagorean Fuzzy Weighted Averaging Aggregation Operators and Their Application to Multiple Attribute Decision Making. J. Math. 2018, 50, 113-129.

25. Liang, D.; Xu, Z. The new extension of TOPSIS method for multiple criteria decision making with hesitant Pythagorean fuzzy sets. Appl. Soft Comput. J. 2017, 60, 167-179. [CrossRef]

26. Biswas, A.; Sarkar, B. Pythagorean fuzzy multicriteria group decision making through similarity measure based on point operators. Int. J. Intell. Syst. 2018, 33, 1731-1744. [CrossRef]

27. Pérez-Domínguez, L.; Rodríguez-Picón, L.A.; Alvarado-Iniesta, A.; Cruz, D.L.; Xu, Z. MOORA under Pythagorean Fuzzy Set for Multiple Criteria Decision Making. Complexity 2018, 2018, 2602376. [CrossRef]

28. Thirumalai, C.; Chandhini, S.A.; Vaishnavi, M. Analysing the concrete compressive strength using Pearson and Spearman. In Proceedings of the International Conference on Electronics, Communication and Aerospace Technology, Coimbatore, India, 20-22 April 2017; pp. 215-218. [CrossRef]

29. Gauthier, T.D. Detecting trends using spearman's rank correlation coefficient. Environ. Forensics 2001, 2, 359-362. [CrossRef]

30. Angeles, L. SAS and SPSS macros to calculate standardized Cronbach's alpha using the upper bound of the phi coefficient for dichotomous items. Behav. Res. Methods 2007, 39, 71-81.

31. Iacobucci, D.; Duhachek, A. Advancing Alpha: Measuring Reliability with Confidence. J. Consum. Psychol. 2003, 13, 478-487. [CrossRef]

32. Gliem, J.A.; Gliem, R.R. Calculating, Interpreting, and Reporting Cronbach's Alpha Reliability Coefficient for Likert-Type Scales. In Proceedings of the 2003 Midwest Research to Practice Conference in Adult, Continuing, and Community Education, Columbus, OH, USA, 8-10 October 2003; pp. 82-88.

33. Ziemba, P.; Becker, J. Analysis of the Digital Divide Using Fuzzy Forecasting. Symmetry 2019, 11, 166. [CrossRef]

(C) 2019 by the authors. Licensee MDPI, Basel, Switzerland. This article is an open access article distributed under the terms and conditions of the Creative Commons Attribution (CC BY) license (http:// creativecommons.org/licenses/by/4.0/). 